\title{
Death-feigning Behavior in the Common Sand Boa, Eryx conicus (Schneider 1801) (Erycidae), and the Common Wolfsnake, Lycodon aulicus (Linnaeus 1758) (Colubridae)
}

\author{
Rahul V. Deshmukh ${ }^{1}$, Sagar A. Deshmukh ${ }^{2}$, Swapnil A. Badhekar ${ }^{3}$, Umesh M. Udapure ${ }^{4}$, and Sheshrao K. Hattimare \\ ${ }^{1}$ H.N. 26, Teacher Colony, Kalmeshwar, Nagpur, Maharashtra-441501, India (rahul30.snake@gmail.com) \\ ${ }^{2}$ Behind Potdar Nursing Home, Kalmeshwar, Nagpur, Maharashtra-441501, India (sd.snakefriend@gail.com) \\ ${ }^{3}$ Tiwaskar Wadi near Boudha Vihar, Hingana Raipur, Nagpur, Maharashtra-441110, India (swapnilbadhekar86@gmail.com) \\ ${ }^{4}$ Near Hanuman Temple, Tidaka Road, Sadak Arjuni District, Gondia, Maharashtra-441807, India (umeshudapure@gmail.com) \\ ${ }_{5}^{5}$ At Wadegaon, P.O. Sadak, Arjuni, Gondia, Maharashtra-441807, India (sheshraohattimare@gmail.com)
}

$\mathrm{D}$ eath-feigning or thanotosis is a form of catalepsy or tonic immobility. In most cases, animals exhibiting this behavior "play dead" by maintaining a rigid posture or by simulating fully relaxed muscles in response to external stimuli, including predation attempts (e.g., Gregory et al. 2007; Bhattarai et al. 2017). In snakes, thanotosis often includes immobility and mouth gaping, frequently with the tongue everted and sometimes involving voluntary supination or lack of muscle tone. This behavior has been rarely documented in Asian snakes (Mirza et al. 2011) and we are aware of only a few records of death-feigning in snakes from India: Checkered Keelback (Fowlea piscator), Copper-headed Trinket Snake (Coelognathus radiatus), and the Common
Wolfsnake (Lycodon aulicus) (Vogel and Han-Yuem 2010; Mirza et al. 2011); Large-eyed False Cobra (Pseudoxenodon macrops) (Bhosale and Thite 2013); Burmese Python (Python bivittatus) (Bhattarai et al. 2017), and Yellow-collared Wolfsnake (Lycodon flavicollis) (Muliya et al. 2018). Herein we describe the first record of death-feigning in the Common Sand Boa (Eryx conicus) and a second record of this behavior in the Common Wolfsnake (Lycodon aulicus).

Common Sand Boas (Eryx conicus) are stout-bodied, medium-sized snakes with strongly keeled scales (Das 2002). The species is abundant in arid localities (Das 2002) and occurs throughout the Indian Subcontinent except for the Andaman and Nicobar Islands (Whitaker and Captain 2004).

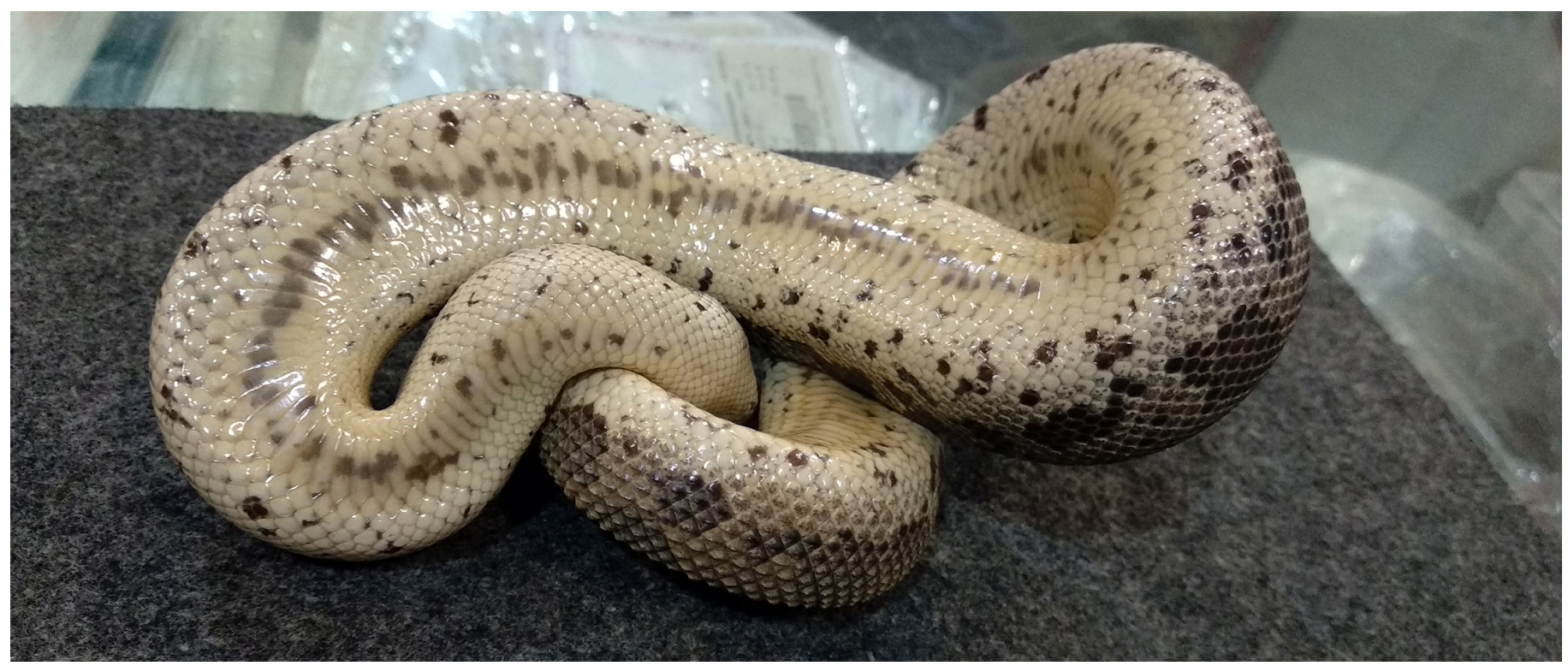

Fig. 1. A Common Sand Boa (Eryx conicus) feigning death in response to capture. Photograph by Umesh M. Udapure. 


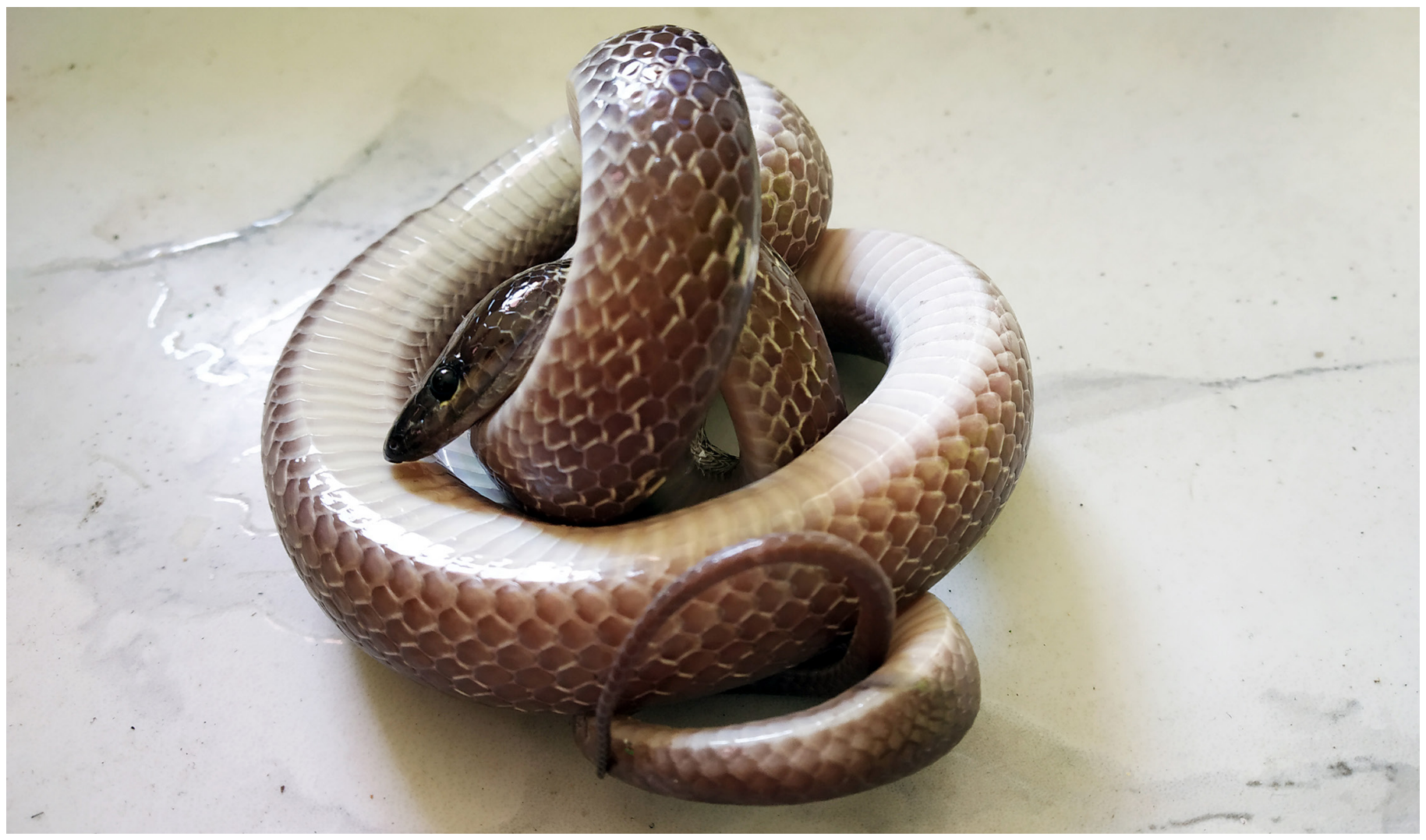

Fig. 2. A Common Wolfsnake (Lycodon aulicus) feigning death in response to capture. Photograph by Rahul V. Deshmukh.

Although mostly crespuscular or nocturnal (Das 2002), these snakes are known to hunt by day (Whitaker and Captain 2004). They are strong burrowers in loose sand or silty soil (Sharma 2007) and generally constrict prey, which includes small mammals, birds, reptiles, amphibians, and even large insects (Smith 1943; Das 2002; Sharma 2007; Whitaker and Captain 2004). Typical foraging behavior is for an individual to hide itself in the substrate or surface litter and ambush any prey that comes within striking range (Whitaker and Captain 2004).

On 21 November 2018, SH rescued an unsexed subadult from Sadak Arjuni, Gondia, Maharashtra, India $\left(21^{\circ} 05^{\prime} 27.7^{\prime \prime} \mathrm{N}, 80^{\circ} 09^{\prime} 14.7^{\prime \prime} \mathrm{E}\right)$, and placed the snake in a plastic container. After about $10 \mathrm{~min}$, the snake stopped moving. When we opened the container to confirm if the snake was dead or alive, it remained motionless except for breathing. We removed it from the container, at which time it inverted half of its body (Fig. 1), defecated, and remained in this position for $12-15 \mathrm{~min}$. We subsequently released the snake in appropriate habitat.

Common Wolfsnakes (Lycodon aulicus) occur throughout India (including Lakshadweep but not the Andaman and Nicobar Islands (Whitaker and Captain 2004). These are among the most frequently encountered snakes on the Indian plains and often occur near and even in human habitations (Daniel 2002). Common Wolfsnakes are strictly nocturnal and feed on geckos, skinks, rodents, and bats (Whitaker and Captain 2004; Tank and Sharma 2016).

On 8 October 2018, RD and Manoj Uikey rescued an adult male near the Sai Temple, Brahmani, Kalmeshwar, Nagpur, Maharashtra, India $\left(21^{\circ} 24^{\prime} 08.81^{\prime \prime N}\right.$, $78^{\circ} 90^{\prime} 86.93^{\prime \prime E}$ ). When placed in a plastic container, the snake stopped moving and turned upside-down. We thought it was dead and removed it from the container, at which time it inverted its entire body (Fig. 2) and remained in this position for $18 \mathrm{~min}$. We subsequently released the snake in appropriate habitat.

The death feigning response might not always occur with the same intensity. For example, neither of our snakes engaged in mouth-gaping, nor did the Common Wolfsnake described by Mirza et al. (2011). Also, this behavior might be correlated with external environmental factors like temperature or humidity (Gerald 2008; Bhosale and Thite 2013). That we collected both of these nocturnal snakes during the day might be noteworthy. However, both initially tried to escape, the Common Wolfsnake bit the rescuer, and both feigned death as last resort.

\section{Acknowledgements}

We are very grateful to Subham Katgube, Shubham Nandeshwar, Kunal Bansod, Swapnil Raut, and Raj Khobragade. 


\section{Literature Cited}

Bhattarai, S., C.P. Pokheral, and B.R. Lamichhane. 2017. Death feigning behavior in the Burmese Python Python bivittatus Kuhl, 1820 in Chitwan National Park, Nepal. Russian Journal of Herpetology 24: 323-326.

Bhosale, H.S. and V. Thite. 2013. Death feigning behavior in Large-eyed False Cobra Pseudoxenodon macrops (Blyth, 1854) (Squamata: Colubridae). Russian Journal of Herpetology 20: 190-192.

Daniel, J.C. 2002. The Book of Indian Reptiles and Amphibians. Bombay Natural History Society, Oxford University Press, Bombay, India.

Das, I. 2002. A Photographic Guide to Snakes and Other Reptiles of India. New Holland Publishers Ltd., London, UK.

Gerald, G.W. 2008. Feign versus flight: influences of temperature, body size and locomotor abilities on death feigning in neonate snakes. Animal Behaviour 75: 647-654.

Gregory, P.T., L.A. Isaac, and R.A. Griffiths. 2007. Death-feigning by grass snakes (Natrix natrix) in response to handling by human "predators." Journal of Comparative Psychology 121: 123-129.
Mirza, Z.A., V.V. Vaze, and R.V. Sanap. 2011. Death feigning behaviour in two species of the genus Lycodon of Asia (Squamata: Colubridae). Herpetology Notes 4: 295-297.

Muliya, S.K., A. Nath, and A. Das. 2018. First report of death feigning behavior in the yellow collared wolf snake (Lycodon flavicolis). The Herpetological Bulletin 143: 41-42.

Sharma, R.C. 2007. The Fauna of India and the Adjacent Countries. Reptilia VolumeIII (Serpentes). Zoological Survey of India, Kolkata, India.

Smith, M.A. 1943. The Fauna of British India, Ceylon and Burma, including the Whole of the Indo-Chinese Sub-region. Reptilia and Amphibia. Vol. III.Serpentes. Taylor and Francis, Ltd., London, UK.

Tank, C. and V. Sharma. 2016. Lycodon aulicus (Common Wolf Snake). Diet. Herpetological Review 47: 480.

Vogel, G. and H.K. Han-Yuem. 2010. Death feigning behavior in three colubrid species of tropical Asia. Russian Journal of Herpetology 17: 15-21.

Whitaker, R. and A. Captain. 2004. Snakes of India: The Field Guide. Draco Books, Chennai, India. 